\title{
Seating Accommodations
}

By KEYES D. METCALF

A COLLEGE or university library must provide seating accommodations for five distinct groups of users-undergraduate students, graduate students, faculty members, visiting scholars, and others. These groups differ sharply in the use they make of a library; in order to estimate the seating that ought to be provided in a new building, one must estimate the needs of each group separately and then add the five estimates. Some of the questions that arise in making each of these estimates will be considered here.

\section{UNDERGRADUATES}

In most institutions of higher learning, though not all, undergraduates are more numerous than the four other groups combined. Statistics reported in the January 1960 issue of $C R L$ show that, in 119 universities giving graduate work, the median number of undergraduates was 6,175 compared to 1,080 graduate students. In colleges and universities of other types, according to the same report, not more than 5 per cent of the students were on the graduate level, and in most cases there were very few or none at all. Undergraduates, then, represent the largest part of the clientele in the libraries with which this article deals. This does not mean that their use of the library will be proportionate to their numbers; that will depend on the character of the institution and its objectives.

It should be made clear that no definite formula can be proposed to determine the percentage of undergraduates whom the library should be capable of seating at one time. Institutions differ widely in the amount of use to be ex-
Dr. Metcalf is Librarian Emeritus, Harvard College Librury.

pected at periods of peak demands, and estimates are still more difficult to make because of uncertainty as to how much the number of undergraduates will increase during the years ahead, for which the building is being planned. It is even harder to predict how much use by the undergraduates will change as the result of changed admissions regulations and educational policies of the institution. In a word, neither the size nor the other characteristics of the student group are constant. Finally, it is not easy to forecast how much a fine, new, comfortable, attractive, and adequate building will increase the demands for seating. And the effect of other possible additions to the institution's building plant should not be forgotten. A new student union, study or library rooms in residential halls, or small private study accommodations connected with dormitory suites will all have an influence on the peak loads. In spite of all these uncertainties, some estimate must be made before plans for a new library are prepared if the institution expects to provide a building large enough for a reasonably long period ahead.

It is suggested that the administrative officers of the college should be responsible for an estimate of the increase in the number of students to be enrolled during the period for which the proposed building is designed to be adequate and that they should also indicate whether there are plans for changes in admissions 
and educational policies that will affect library use. If past experience gives any indication of future developments, proportionate use should increase rather than decrease, even without policy changes and in spite of the increased vogue of paperbacks owned by the students; this results from a gradual rise in the calibre of the student body and increasing demands on space in other buildings. Experience in practically all institutions with library buildings completed since World War II indicates that when a well-planned, comfortable, and attractive building is provided, use will increase tremendously, sometimes even doubling or tripling if the space provided makes it possible.

But there are other important factors which may sooner or later have a bearing on this problem of the number of required seats. Is the library service to undergraduates to be centralized in the proposed new structure? If the university is a large one with departmental libraries, how much of the service to undergraduates will be provided outside the main building? Is it a residential institution with students living in the immediate neighborhood who can be expected to use the library heavily in the evening, or

Dr. Metcalf is engaged in preparing a book on the planning of college, university, and research library buildings. "Seating Accomodations" is the preliminary version of a chapter from that volume which CRL is pleased to publish here as the fourth of a series of excerpts from it.

Dr. Metcalf invites suggestions and comments for consideration for use in the final version of his work.

The research for his book and the writing of it is being done by Dr. Metcalf as the director of a special project sponsored by a grant from the Council on Library Resources (CRL, XI (1960), 136). is the student body largely a commuting one that leaves the campus as soon as possible after classes are over? Are there a large number of evening students? This is often the case in a city institution; generally, however, if both the day and evening students commute, they do not use the facilities at the same time. If it is a residental institution with most of the students living in dormitories on the campus, is it in a city where there are many attractions outside the campus, day after day? or is it a comparatively rural situation where there are few outside activities that attract the students, particularly during weekday evenings? Is it coeducational? Men and women tend to try to study together, so coeducation increases library use.

Does the institution provide special reading rooms and library collections in the residential halls, as is done in the Yale colleges, the Harvard houses, and the larger dormitories in many public and private institutions today? Are the dormitories so congested and are student customs such that the dormitory rooms are not suitable for study? If so, the student who wants to work will find that he must go to the library to study, except perhaps between 1 and 7 A.M. What are the library hours? Is it open until midnight on weekday evenings or only until 9 or 10 . If it is in a residential institution with heavy evening use, is that use staggered, with some students spending the early evening at the library, while others go to the movies and then to the library from 10 to 12 , reducing the percentage who can be expected at any one time? All of the foregoing questions suggest problems that ought to be considered, though they may do little to help the person drawing up the program in deciding on the number of seats that should be available to undergraduate students in his particular institution.

The following additional questions should also be considered by the program writer, although, like those that 
have been suggested above, they have no answers that can be translated into exact figures. Does the library expect to be able to take care of the peak demands which tend to come just before and during the beginning of the examination period or during the reading period, if there is one? These are by all odds the times of heaviest library use. They may also be the times when the students are most anxious to study and when dormitory rooms may be more suitable for that purpose than at other periods. At such times students may be willing and able to study at large tables in a reading room with chairs closer together than at other times in the academic year. Is the institution prepared during this time of peak loads to have the students use facilities outside the library, such as study halls, seminars, and classrooms, on the basis that it cannot afford to increase the size of its library by as much as 20 per cent for the convenience of its students during perhaps only fifty hours in the academic year?

Does the library encourage students to study their own books in the library on the basis that a more studious atmosphere will prevail there than elsewhere and that study with reference material immediately at hand tends to be worthwhile?

Does the institution expect to assign seats in the library for honor students? Whenever a seat is assigned to one student exclusively and cannot be used by others, it increases the total number of seats required, because no student to whom a seat is assigned will use it during all hours of the day or even all the hours when the peak load is expected. For instance, if 25 per cent of the students are honor students and a seat is assigned for each of them, then the additional number of seats beyond that 25 per cent must take care of the other 75 per cent of the total student body who may study almost as much as the honor students during the peak loads. The writer does not recommend assignment of seats to undergraduates. Very few institutions can afford to have a library large enough for this purpose. At Harvard 60 per cent of the undergraduates go out for honors, and even more at Radcliffe; if each honor student were assigned a seat for exclusive use, the total seating accommodations now available would be completely inadequate.

W. W. Bishop, one of our wisest librarians, frequently recommended that libraries be prepared to seat half of the entire student body at the time of peak loads, but until a few years ago the writer of this volume, who had a reasonably wide acquaintance among the libraries of the country, knew of no institution that ever had a well-authenticated record of over 40 per cent of the undergraduate student body in its library or libraries at one time. However, since 1950 he has learned of a number that, on occasion, have had as many as 50 per cent. These are unusual institutions with students of the highest quality. They are in a rural area or a small town and in most cases are coeducational. It is suggested that institutions of this kind be prepared to seat at least half of the undergraduate student body at one time, and, of course, if the institution is expected to grow in the years for which the library is being planned, this may mean a considerably larger percentage of the present student body. A Harvard University, with a high-grade student group in a metropolitan area, the librarian estimated some years ago that if the library provided for three out of eight of the undergraduate students at one time in either the house libraries, departmental libraries, the research library, or the undergraduate library, that should be sufficient. So far this has proved to be the case, although the pressure for seating becomes unpleasantly heavy during the reading and early examination periods, and, in this widely decentralized library, certain units are frequently in- 
adequate, so students in order to find a seat may have to go to a building other than the one he would prefer.

A few years ago the writer suggested at the University of Florida that at the time of the peak load up to 75 per cent of the students could be expected to be studying at one time and that half of this 75 per cent would, or at least could, properly use their own rooms during the peak periods of demand. This would leave $37 \frac{1}{2}$ per cent to be cared for elsewhere. It was then suggested that a fifth of this number, or $71 / 2$ per cent, might well be cared for in reading or study rooms in the residential halls, and that of 30 per cent remaining, a third would find their study facilities in departmental libraries, leaving 20 per cent to be cared for in the central building. In a great city university, such as New York University, with more than forty thousand students registered altogether, but with a very considerable number of parttime and evening students, the university probably should not, and actually could not, consider providing in all of its decentralized libraries for more than 10 per cent of the total student enrollment at any one time.

Consideration of accommodations for students in undergraduate professional schools should not be forgotten. These may include law, medicine, divinity, educational, public health, dentistry, pharmacy, nursing, veterinary medicine, architecture, engineering, home economics, agriculture, and physical education among others. Lilbrary needs of these diverse fields are by no means identical.

Nothing has been said of departmental libraries for disciplines in the arts and sciences; i.e., humanities, social sciences, and sciences. It should always be remembered that departmental libraries tend to proliferate, and unless this tendency is kept under control, the cost to the institution may become very high. At Harvard University there are over ninety libraries in all, and similar situations, gen- erally on a smaller scale, may be found in a good many of our large universities; some of the libraries are definitely recognized as part of the university library, while others simply have grown up, with the university library more or less unaware of their existence. This decentralization has been carried even farther in some German and Japanese universities.

A study of the situation should be made in each institution, and this statement can at best provide only some worthwhile guide lines that may help in solving the problem. No clear rules can be suggested for determination of needs, but most of the factors involved have been described, and it should be emphasized that each institution must study its problem carefully with the years ahead, as well as the present and the immediate future, in mind. The difficulties of estimating future needs make it obvious that, unless an institution is ready to start all over again with completely new library facilities every generation or even more frequently, its library should be planned in such a way that additions can be made without handicapping it aesthetically, functionally, or as a vital part of the educational program.

It can be suggested here that twentyfive square feet per student to be housed in the reading areas be used in the preliminary estimates; that careful planning should make that figure adequate. This does not include space outside the reading areas which is often primarily for use of students.

\section{Graduate Students}

Graduate students in arts and sciences or those working for an advanced degree in professional schools represent a somewhat different problem from undergraduates in liberal arts or the professions, both in respect to the square footage required per seat and the percentage of students for which seats should be provided. Each graduate professional school is likely to have its own special depart- 
mental library, and the percentage of students requiring seating accommodations at any one time in each of these libraries may well be determined after consideration of the points dealt with in the preceding section, but with a separate calculation for each professional school. In general, the percentage of seats required would tend to be larger than for undergraduates, particularly in law schools where up to 50 per cent or, in a few schools, even more are likely to want to use the library at one time. City institutions with many part-time students are certainly an exception to this statement. In a medical school the percentage will be considerably smaller as so much time is required in laboratory and clinical work, and similar factors are to be considered in engineering and technological institutions. It is graduate students in arts and sciences, particularly in the humanities and social sciences, who ordinarily require seats for the largest percentage of their number. Those working in the sciences resemble the medical and engineering students; they spend so much of their time in laboratories that library demands are decreased because there are only twenty-four hours in the day, if for no other reason.

Graduate students make heavier use of the library than undergraduates, and it may also be suggested that, for students working for the master's degree, some $\mathbf{2 0}$ per cent more space for each seat should be provided than for those working for the bachelor's. Thirty square feet per seat is proposed.

It is the graduate students in the humanities and social sciences working for the doctorate who will make the largest proportional demands on the library in the percentage of seats required. There is ordinarily a great difference between those doing the first and second year of their work toward the Ph.D. and those who are engaged in writing their dissertations in these fields. Many institutions would agree that any man or woman who is actually writing a doctoral dissertation in the humanities or social sciences should have at his disposal an assigned library seat, preferably at an individual table or in a carrel and with a bookshelf, for the full period when he is occupied with this task and that 40 per cent more space than is provided for each undergraduate, or thirty-five square feet, is none too much. Let us say then that in the average institution there should be a seat in the library for every man actually working on his dissertation in the humanities and social sciences; that for others working for the Ph.D. but not yet engaged in writing the dissertation, one seat for every two full-time students should generally be sufficient; for those working for the master's a seat for 40 per cent might do in many universities, depending on local conditions. Circumstances in each institution will vary, and these estimates should not be accepted blindly. This is one of the points on which an experienced library consultant may be helpful.

The square footage areas proposed above-twenty-five for undergraduates, thirty for graduate students in their first year, and thirty-five for each one engaged in dissertation writing-are for carefully laid out, nonmonumental space, none of it in closed locked carrels. If closed carrels are to be provided, not less than forty to fifty square feet is required for each, unless the partitions are nothing more than gratings, such as are found in the Rutgers University Library. This includes their share of adjacent aisle spaces. All these figures are for reading space, and it must not be forgotten that a very considerable amount of square footage is required elsewhere in the building for other sern ices to readers.

\section{FACULTY}

Faculty members have needs different from those of undergraduate or graduate students, and estimating the space that should be provided for them is even 
more difficult than for the other groups. Customs and habits vary a great deal between institutions. If adequate library facilities for faculty members have been provided in the past, it is probable that many faculty members in the humanities and social sciences will prefer to do most of their research and preparation for lectures in the library. In other institutions, if facilities have not been satisfactory and particularly if faculty members live close to the campus, many of them will prefer to work in their own homes, believing that they may be less likely to be disturbed there. However, as houses and apartments tend to grow smaller, they become less suitable places to study, and it should be noted that, for younger faculty members with children at home, the house may not be a satisfactory place to cairry on research. Also, a considerable percentage of these persons in many institutions are still working on their dissertations, and satisfactory quarters for research are of great importance. In general, there is less demand proportionately for faculty studies in colleges than in universities. Many universities have felt that they could provide library faculty studies for senior members of the faculty only, although these men may need such accommodations less than their juniors. The institution's policy in regard to faculty offices in other buildings also affects demands for studies in the library. For many faculty members a study in the library, as well as an office elsewhere, may be useful.

While the number of faculty members may exceed 10 per cent of the number of students in some institutions, it is suggested that this can be left out of calculation in connection with seating capacity in the regular public reading rooms of the library. This is not because faculty members do not read, but because their heaviest library use tends to be in quarters specially assigned for them or in the reference room, at the public catalog, or in the periodical room, and even there they are not likely to stay for any long periods and to add to congestion.

Regardless of this, provision must be made for them. It can be done in three ways: in a special faculty reading room; in faculty studies; or in the type of cubicle provided by the library for its graduate students. The dividing line between graduate students and faculty is not always clear, of course; in the case of teaching fellows the facilities ordinarily assigned to graduate students are usually considered sufficient, but the older men are seldom satisfied with these.

While it has not been unusual to provide special faculty reading rooms, their value is questionable. Faculty members doing research or writing lectures prefer to be alone, rather than in a reading room, even if its use is restricted to their colleagues.

The great problem in connection with faculty members is studies. How many should there be, and how large? As is already indicated, the number to be provided will vary a great deal from institution to institution. It is suggested that if quarters for the faculty in the library are intended for use as studies only, and not also as offices, the number can be very much reduced. Most professors who are doing administrative work or who require frequent consultation with students do not like to do this in their library studies and prefer an office in a departmental or other building. It is suggested that faculty members in the sciences are better satisfied with their studies or offices in the science buildings and that the same will be true for a certain percentage, varying in each institution, of those in the humanities and the social sciences. No attempt is made here to suggest the percentage of the faculty members who should have studies in a central library building. This is a good problem to place before the library committee and possibly a library consultant on building planning. Many faculty studies in many institutions are assigned to men who use them 
so rarely as to make them a luxury as far as the institution is concerned. Studies should be assigned for limited periods only, and assignments renewed only when the need is clearly demonstrated. On the other hand, it should not be forgotten that much of the valuable research carried on in our academic institutions is greatly facilitated by faculty studies.

But there is another problem. How large should the study be? An examination of libraries built during this century will show studies all the way from well over two hundred square feet down to no more than one-sixth of that figure. The program should give some indication as to the number of studies and their average size, and it is suggested that a preliminary estimate of seventy-five square feet each can well be used until a detailed study of requirements is made locally and the architect has made his suggestions.

Five additional problems in connection with faculty studies should be kept in mind, and preparation should be made to deal with them:

1. Faculty members as a group, whatever their politics or economic outlook, are ultraconservative in their study habits and do not change them readily.

2. Few faculty members like to share a study with another, and it is much better to provide two rooms with as little as fifty to sixty square feet in each than one with twice that amount with two men assigned to it. Of course, a single room is sometimes satisfactory for two men with schedules so different that they would not be using the room at the same time, and then the larger study might be desirable, but this is an unusual situation.

3. In a university, or a college for that matter, where research is emphasized and productive writing a requirement for promotion, a larger number of faculty studies should be provided than in an institution where there is primarily a teaching rather than a research faculty. Many college libraries find that the demand for faculty studies has been or may still be quite small, but as years go by and research is emphasized more and more and standards rise, the demand for studies will tend to increase as it does for research collections. The writer recently made a survey of libraries in the state of Maine and found a great demand for studies and research material in one institution, while in another, also with a good national reputation but with a teaching rather than a research faculty, the demand was almost nonexistent.

4. The difference between a faculty study and an office should not be forgotten. If the institution provides most faculty members with conveniently located offices on the campus, the demand for studies in the library will be greatly reduced. If faculty studies in the library must serve as offices also, the demand for them will increase, and, unless they are placed where students can reach them readily, they may prove a disturbing factor in the library. Faculty offices are not recommended for the library.

5. If faculty studies are not satisfactorily lighted and ventilated, complaints are sure to arise; if they have no outside windows and contain less than seventyfive square feet, they may present a problem for anyone with a tendency toward claustrophobia, but if a very considerable percentage of faculty members are to have studies and have them with windows, there will be little window space for other purposes. To get around this problem, they have sometimes been placed on top floors facing light courts which go down only to that floor. One difficulty with this solution is that it houses professors at a considerable distance from the books in their subject fields.

\section{Visiting Scholars}

This group will be a comparatively negligible factor in a great majority of institutions, but in a few of the largest and best university libraries, particularly 
those in large cities or on the way to and from vacationland, it may be important. At Columbia University and Harvard the burden may be greatest, but in any one of the fifteen or twenty largest research libraries the problem of visiting scholars should be considered seriously in building planning. Dartmouth College in upper New England, with a superb college library, is another institution used heavily by visiters, at least during the summer months. Only local experience can serve as a basis for estimating the requirements, but they should be carefully studied.

At Harvard University the central library could make good use of twenty-five studies for visiting scholars, in addition to fifty carrels in Widener alone for a large part of the year, both summer and winter, and as many more would be useful in the departmental libraries.

\section{Others}

Visitors who are not scholars can generally be ignored in estimating seating requirements but should not be forgotten because of the problem they may present. Their number is not necessarily negligible. In any good college or university library, graduates of the institution are generally welcome. High school and college students from other local institutions with poorer libraries can be expected to pour in if they are encouraged to do so; indeed, unless they are discouraged. Here the decision as to what to do with them is a policy one for the institution's administration after the librarian has set forth the situation in detail. The time when a new building is being planned is a suitable one for the consideration of the problem at the highest level.

\section{The Habit of Thinking}

The reading of some stray pages of a tattered book, or the accidental listening to some instructive conversation, has kindled to a flame that desire of knowledge, which is found in the breasts of all. The train of thought or inquiry, casually started, is pursued. The mind becomes conscious of its powers, and learns that there are sources of enjoyment, to which it had before been a stranger. The little intervals of labor, and even many of those hours which had otherwise been devoted to relaxation and repose, are given to patient, persevering toil in the acquisition of knowledge. A valuable book is a treasure, and the conversation of a well informed man, a rich entertainment. And with the increase of the stores of knowledge, come the busy workings of the mind. The habit of thinking, - that all important habit, which more than any thing else leads to intellectual superiority, is formed. Our scholar, like the devoted poet or painter, is always, and everywhere, a learner. Every fact he meets, every remark he hears, every book he reads, furnishes matter for reflection; and the powers of the mind, called into constant and vigorous exercise, are daily growing in strength.-From Address Delivered Before the Benevolent Society of Bowdoin College, Tuesday Evening, Sept. 5, 1826. By Samuel P. Newman. (Portland: 1826). 